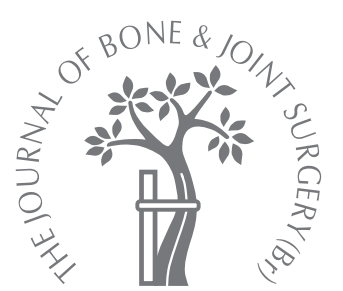

J. D. Calder,

A. L. Hine,

M. F. Pearse,

P. A. Revell

From North

Hampshire Hospital

NHS Foundation

Trust, Basingstoke, England

\section{The relationship between osteonecrosis of the proximal femur identified by MRI and lesions proven by histological examination}

Total hip replacement in patients with advanced osteonecrosis of the femoral head is often complicated by early loosening of the femoral component. Recent evidence has suggested that abnormal bone extending into the proximal femur may be responsible for the early failure of the femoral component. We aimed to identify which patients were at high risk of early failure by evaluating gadolinium-enhanced MR images of histologically-confirmed osteonecrotic lesions beyond the femoral head.

Although the MR signal intensity has been shown to correlate well with osteonecrosis in the femoral head, it was found to be relatively insensitive at identifying lesions below the head, with a sensitivity of only $51 \%$ and a predictive value of a negative result of only $48 \%$. However, the specificity was $\mathbf{9 0 \%}$, with the predictive value of a positive MRI finding being $86 \%$. Only those patients with osteonecrosis of the femoral head secondary to sickle-cell disease, who are known to be at high risk of early loosening, had changes in the MR signal in the greater trochanter and the femoral shaft. This observation suggests that changes in the MR signal beyond the femoral head may represent osteonecrotic lesions in areas essential for the fixation of the femoral component. Pre-operative identification of such lesions in the neck of the femur may be important when considering hip resurfacing for osteonecrosis of the femoral head, following which early loosening of the femoral component and fracture of the neck are possible complications.

Orth), Fellow of Faculty Sport and Exercise Medicine,

Consultant Orthopaedic

Surgeon and Clinical Senior

Lecturer

Imperial College London, Charing Cross Campus,

Reynolds Building,

St Dunstan's Road,

London W6 8RP, UK.

= A. L. Hine, MRCP, FRCR, Consultant Radiologist

Department of Radiology

M. F. Pearse, FRCS(Orth),

Orthopaedic Surgeon

Department of Orthopaedic

Surgery

Central Middlesex Hospital,

Acton Lane, London NW10

7NS, UK.

In P. A. Revell, PhD, FRCPath, Professor Emeritus

University College London,

Eastman Dental Institute, 256

Grays Inn Road, London WC1X 8LD, UK.

Correspondence should be sent to $\mathrm{Mr}$ J. D. F. Calder at

North Hampshire Hospital,

Aldermaston Road, Hampshire

RG24 9NA, UK; email:

j.calder@ic.ac.uk.

(C)2008 British Editorial Society of Bone and Joint Surgery doi:10.1302/0301-620X.90B2. $19593 \$ 2.00$

$J$ Bone Joint Surg [Br] 2008;90-B:154-8.

Received 24 April 2007;

Accepted after revision 3

September 2007
Magnetic resonance imaging is well established as the method of choice for investigating the early stages of osteonecrosis of the femoral head and asymptomatic contralateral disease. ${ }^{1-5}$ This is a painful and progressive condition which often affects younger patients. ${ }^{6,7}$ Multiple aetiologies have been described which predispose to its development, and up to half of such patients may have asymptomatic disease in the opposite hip. ${ }^{8}$ Early detection of osteonecrosis may lead to surgical intervention and prevention of the complications which follow collapse of the femoral head. The use of gadolinium-enhanced MRI has recently been shown to improve the diagnosis of the early stages of the condition. ${ }^{9,10}$

Progression of the disease often leads to collapse of articular cartilage and the development of disabling secondary osteoarthritis (OA). In the United States it has been reported that up to $12 \%$ of all patients undergoing total hip replacement (THR) have OA secondary to osteonecrosis of the femoral head. ${ }^{11}$ However, one review of the literature has suggested that such treatment has a high rate of early failure because of loosening of the femoral compo- nent. ${ }^{12}$ Recent studies have also indicated that isolated resurfacing of the femoral head for osteonecrosis has a higher risk of failure of the femoral component than was originally thought. ${ }^{13,14}$ Relief from pain and the Harris hip score ${ }^{15}$ are poorer in hip resurfacing for osteonecrosis than those for THR and some authors have reported that more than half of their patients require revision for pain within two years. ${ }^{16,17}$ At present, it is impossible to predict pre-operatively which patients are at risk of early failure of the femoral component.

Recently, the presence of histologicallyabnormal bone in regions of the femur crucial for the fixation of the resurfacing implant has been demonstrated, and this may be a contributing factor in premature loosening. ${ }^{18}$ It has been suggested that osteonecrosis is a factor in the mechanism of failure of the femoral component and of fracture of the femoral neck in patients undergoing hip resurfacing procedures. $^{19,20}$ The positive correlation between the histological findings of osteonecrosis and the intensity of the MR signal in the femoral head before operation is well documented. ${ }^{21-23}$ However, there are no reports on the changes 
in the intensity of the signal extending beyond the femoral head into those regions of the proximal femur required for fixation of the component.

Our aim was to correlate the MR signal changes with the histology of bone samples from four regions beyond the femoral head in patients undergoing THR for osteonecrosis of the femoral head. It was postulated that detection of abnormal bone in the proximal femur by changes in the MR signal in the femoral neck could be used to predict which patients would be at risk of early failure of the femoral component in particular and which patients therefore would be unsuitable for hip resurfacing.

\section{Patients and Methods}

After obtaining the approval of the ethical committee, 15 symptomatic patients with advanced osteonecrosis of the femoral head on plain radiography (ARCO stage III or stage IV according to the criteria of Ficat and Arlet ${ }^{24}$ ) had MRI of their proximal femora. ${ }^{25}$ The osteonecrosis of the femoral head was secondary to the administration of steroids in six patients, sickle-cell disease in four, alcohol abuse in two and was idiopathic in three (Table I). All the patients underwent THR within four months of having MRI.

Magnetic resonance imaging was performed using a 1.5 T Elscint Gyrex scanner (Gyrex; Elscint Ltd, Haifa, Israel). Coronal and sagittal sections of $5 \mathrm{~mm}$ thickness were taken at intervals of $2.5 \mathrm{~mm}$ of both proximal femora. Relative T1-weighted spin-echo (SE) images (repetition time (TR) $600 \mathrm{~ms}$, echo time (TE) $20 \mathrm{~ms}$ ) and T2-weighted SE images (TR $2600 \mathrm{~ms}$, TE $90 \mathrm{~ms}$ ) were taken for all patients. In addition, inversion recovery fat-suppressed images (STIR-TR $2600 \mathrm{~ms}$, TE 25 ms, T1 110) were obtained.

After these sequences had been taken, $0.2 \mathrm{ml} / \mathrm{kg}$ of Magnevist contrast (Bayer Schering Pharma AG, Berlin, Germany) was administered intravenously (1 ml Magnevist $=469 \mathrm{mg}$ of dimeglumine gadopentetate). Coronal contrast-enhanced T1-weighted SE images were obtained 30 minutes after injection.

All the images were reviewed in conjunction with preoperative anteroposterior plain radiographs of the pelvis. Osteonecrosis of the femoral head was classified according to the ARCO classification. The radiologist (ALH) was unaware of the underlying cause of the osteonecrosis. ${ }^{25}$ Images of the contralateral femoral head were also examined and graded as part of the clinical screening process for asymptomatic disease. The presence of an abnormal change in the signal consistent with osteonecrosis was recorded for each of the four areas of the proximal femur beyond the femoral head (Fig. 1).

During THR, the head was harvested for histological confirmation of osteonecrosis and graded according to the classification of Arlet and Durroux. ${ }^{26}$ Biopsy samples of cancellous bone were also taken from the four regions of the proximal femur, examined for evidence of osteonecrosis

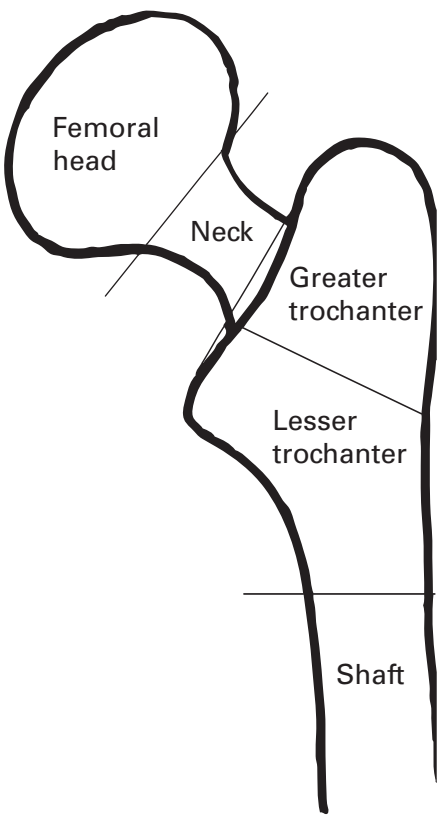

Fig. 1

Diagram showing the five regions of the proximal femur in which abnormalities in the MR signal were recorded.

and graded according to the method described by Humphreys et al. ${ }^{25}$ The histological presence or absence of osteonecrosis was recorded for each of the four areas and compared with the MRI findings. The pathologist (PAR) was unaware of these and the underlying cause of the osteonecrosis.

Statistical analysis. The agreement between an abnormal signal intensity on an MR image and abnormal histology was assessed by the use of a kappa statistic. The presence or absence of osteonecrosis in each sample was considered to be the most statistically reliable method of assessment. The closer the kappa value was to 1.0 in each region, the stronger the agreement. Therefore, the strength of the agreement was deemed to be poor at a kappa value $\leq 0.20$, fair at 0.21 to 0.40, moderate at 0.41 to 0.60 , good at 0.61 to 0.80 and very good at 0.81 to 1.0 .

\section{Results}

All 15 patients had evidence of advanced osteonecrosis of the femoral head on plain radiography and MRI. The diagnosis was confirmed by histological examination of the femoral head.

Magnetic femoral imaging of the proximal femur. Abnormal signal intensity was present beyond the head in 10 of the 15 patients, but only five of these had changes extending beyond the neck (Table I, Figs 2 and 3). Histologicallyabnormal regions which were normal on standard SE T1and T2-weighted or STIR images did not show enhancement on post-contrast T1-weighted sequences. 
Table I. Details of MRI and histological findings in the 15 patients

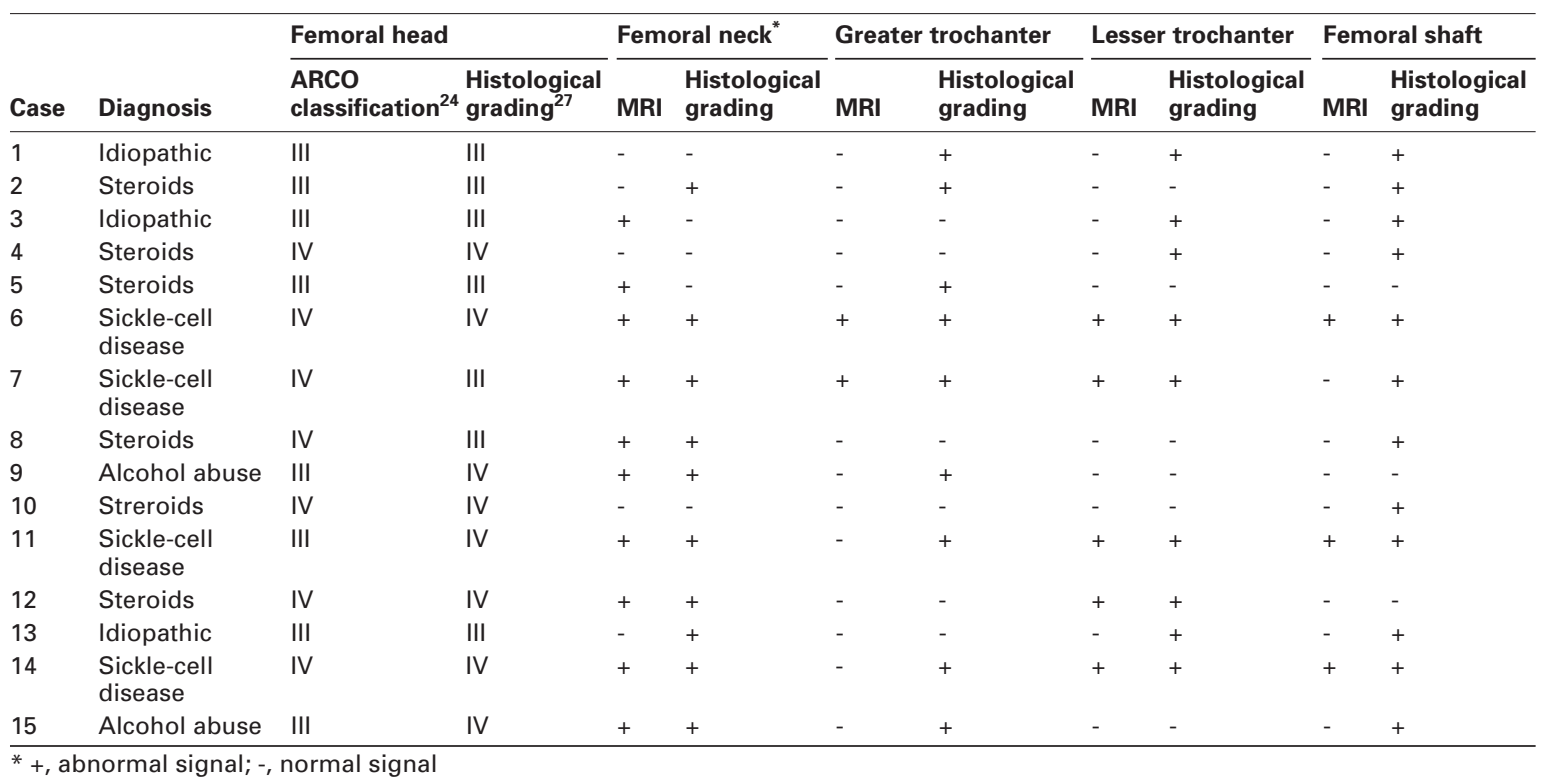

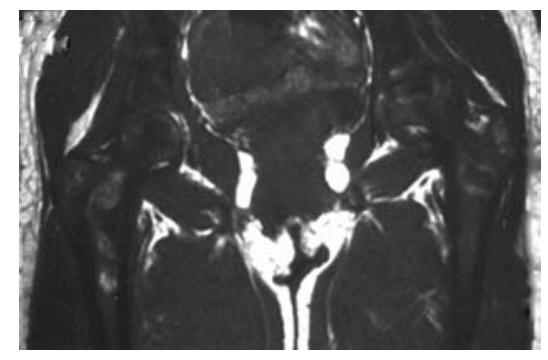

Fig. 2a

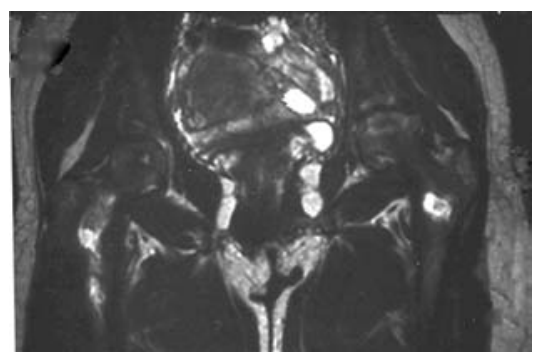

Fig. 2b

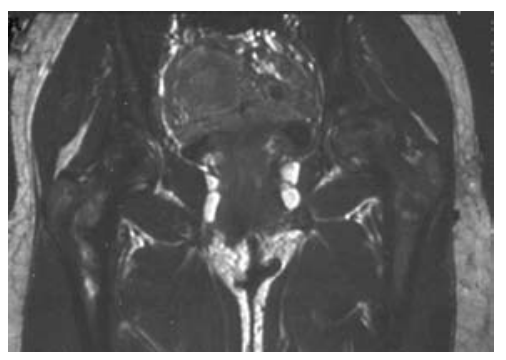

Fig. 2c

MR images of both hips and proximal femora showing abnormal signal changes beyond the femoral heads in areas of histologically confirmed osteonecrosis in a) T1, b) T2- and c) gadolinium-enhanced sequence.

In total, 40 of the 60 regions of the proximal femur had abnormal histology, but only 20 had abnormal changes in the MR signal. However, eight of the ten patients with histological abnormalities in the femoral neck had abnormal MR changes. Beyond the femoral neck MR changes were present in only 10 of 30 regions with abnormal histology. Statistical analysis demonstrated a poor agreement between MR changes and histological findings for the greater trochanter and femoral shaft with fair agreement in the femoral neck and moderate agreement in the lesser trochanter (Table II).

Overall, MRI was relatively insensitive in detecting osteonecrosis beyond the femoral head, with a sensitivity of $51 \%$ and a predictive value of a negative result of $48 \%$. However, the specificity was $90 \%$ with the predictive value of a positive MR finding of $86 \%$.

\section{Discussion}

The positive correlation between MRI and the histological findings of osteonecrosis in the femoral head has been noted previously. ${ }^{21-23}$ We found that osteonecrosis may occur beyond the femoral head and that these areas may be demonstrated by MRI. Hip resurfacing has been advocated as a method of treatment for advanced osteonecrosis of the femoral head since such patients are often young and active. ${ }^{28}$ However, recent clinical reports on the results of isolated resurfacing for osteonecrosis have been less promising with regard to relief from pain and the clinical outcome. ${ }^{16,17}$ Early failure of the femoral component and fracture of the femoral neck have been described after hemi- and full resurfacing. ${ }^{14,20,29}$ It has been suggested that osteonecrosis in the femoral neck may play an important role in this failure. ${ }^{30} \mathrm{~A}$ compromised oxygen concentration 


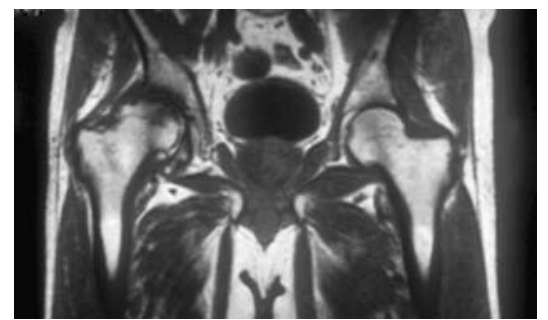

Fig. 3a

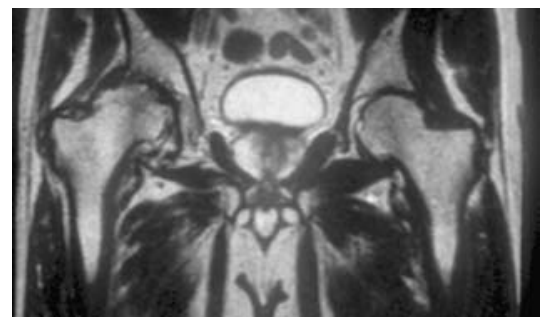

Fig. $3 b$

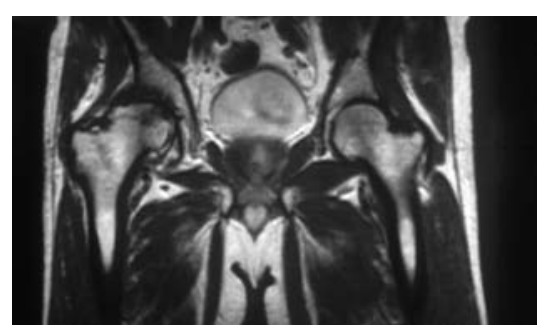

Fig. 3c

MR images of a patient with steroid-induced osteonecrosis of the femoral head showing normal signal intensity in the neck, greater trochanter and shaft on a) T1, b) T2 and c) gadolinium-enhanced sequences despite histological evidence of osteonecrosis in these areas.

and even complete disruption of the blood supply to the femoral head of patients undergoing hip resurfacing have also been documented. ${ }^{19}$

Identification by MRI of histologically-confirmed osteonecrotic lesions beyond the femoral head has not been previously reported. We believe that our study provides further concern regarding adequate support of the femoral component and fixation in hip resurfacing for osteonecrosis of the femoral head. Extension of the osteonecrotic process beyond the head may have a role in the early failure of such components.

Nelson et $\mathrm{al}^{14}$ noted that the rate of failure of hemiresurfacing was higher in those patients with sickle-cell disease than in those with other underlying aetiologies. In our study, those patients with sickle-cell disease also had an abnormal MR signal in all regions of the femur and abnormal histology in all biopsy specimens. ${ }^{31-33}$
Table II. Comparison of MRI and histological findings and regional kappa values

\begin{tabular}{|c|c|c|c|c|c|}
\hline \multirow[b]{2}{*}{$\begin{array}{l}\text { Region of } \\
\text { femur }\end{array}$} & \multirow[b]{2}{*}{ MRI } & \multicolumn{2}{|c|}{ Histology } & \multirow[b]{2}{*}{$\begin{array}{l}\text { Kappa } \\
\text { value }\end{array}$} & \multirow[b]{2}{*}{ Result } \\
\hline & & Normal & Abnormal & & \\
\hline \multirow[t]{2}{*}{$\begin{array}{l}\text { Femoral } \\
\text { neck }\end{array}$} & $\begin{array}{l}\text { Normal } \\
\text { Abnormal }\end{array}$ & $\begin{array}{l}3 \\
2\end{array}$ & 2 & 0.40 & Fair \\
\hline & & & 8 & & \\
\hline \multirow{2}{*}{$\begin{array}{l}\text { Greater } \\
\text { trochanter }\end{array}$} & Normal & 6 & 7 & 0.19 & Poor \\
\hline & Abnormal & 0 & 2 & & \\
\hline \multirow{2}{*}{$\begin{array}{l}\text { Lesser } \\
\text { trochanter }\end{array}$} & Normal & 6 & 4 & 0.50 & Moderate \\
\hline & Abnormal & 0 & 5 & & \\
\hline \multirow{2}{*}{$\begin{array}{l}\text { Femoral } \\
\text { shaft }\end{array}$} & Normal & 3 & 9 & 0.12 & Poor \\
\hline & Abnormal & 0 & 3 & & \\
\hline
\end{tabular}

Our study has demonstrated MR signal changes beyond the femoral head in regions of the femur with histologically-confirmed osteonecrotic lesions. However, MRI was relatively insensitive in identifying these changes, but in those patients in whom they occurred in the femoral neck on the pre-operative MR image, there may be an increased risk of developing early prosthetic failure or fracture of the femoral head.

In order to determine the clinical relevance of abnormal MR signal changes extending into the proximal femur, a larger longitudinal study is required with follow-up of patients until failure of the femoral component has occurred.

No benefits in any form have been received or will be received related directly or indirectly to the subject of this article.

\section{References}

1. Bluemke DA, Zerhouni EA. MRI of avascular necrosis of bone. Top Magn Reson Imaging 1996;4:231-46.

2. Genez BM, Wilson MR, Houk RW, et al. Early osteonecrosis of the femoral head: detection in high-risk patients with MR imaging. Radiology 1988;168:521-4.

3. Glickstein MF, Burk DWR, Schreibler ML, et al. Avascular necrosis versus other diseases of the hip: sensitivity of MR imaging. Radiology 1988;169:213-15.

4. Mitchell DG, Rao VM, Dalinka MK, et al. Femoral head avascular necrosis: correlation of MR imaging, radiographic staging, radionucleotide imaging and clinical findings. Radiology 1987;162:709-15.

5. Thickman D, Axel L, Kressel HY, et al. Magnetic resonance imaging of avascular necrosis of the femoral head. Skeletal Radiol 1986;15:133-40.

6. Solacoff D, Mont MA, Krackow KA. Uncemented total hip arthroplasty in patients less than 45 years with avascular necrosis. Orhop Trans 1993;17:1085.

7. Urbaniak JR, Coogan PG, Gunneson EB, Nunley JA. Treatment of osteonecrosis of the femoral head with free vascularised fibular grafting: a long-term follow-up study of one hundred and three hips. J Bone Joint Surg [Am] 1995;77-A:681-94.

8. Mulliken BD, Renfrew DL, Brand RA, Whitten CG. The prevalence and natural history of early osteonecrosis (ON) of the femoral head. lowa Orthop J 1994;14:11519.

9. Uberoi R, Tai G, Hughes PM. Gadolinium-DTPA enhanced MRI in the evaluation of osteonecrosis. Clin Radiol 1994;49:645-8.

10. Vande Berg B, Malghem J, Labaisse M, Noel H, Maldague B. Avascular necrosis of the hip: comparison of contrast-enhanced and non-enhanced MR imaging with histologic correlation. Radiology 1992;182:445-50.

11. Mankin HJ. Non-traumatic necrosis of bone (osteonecrosis). N Engl J Med 1992:326:1473-9 
12. Mont MA, Hungerford DS. Non-traumatic avascular necrosis of the femoral head. J Bone Joint Surg [Am] 1995;77-A:459-74.

13. Beaulé PE, Schmalzried TP, Campbell P, Dorey F, Amstutz HC. Duration of symptoms and outcome of hemiresurfacing for hip osteonecrosis. Clin Orthop 2001;385:736-40.

14. Nelson CL, Walz BH, Gruenwald JM. Resurfacing of only the femoral head for osteonecrosis: long-term follow-up study. J Arthroplasty 1997;12:736-40.

15. Harris WH. Traumatic arthritis of the hip. J Bone Joint Surg [Am] 1969;51-A:737-55

16. Mont MA, Rajadhyaksha AD, Hungerford DS. Outcomes of limited femoral resurfacing arthroplasty compared with total hip arthroplasty for osteonecrosis of the femoral head. J Arthroplasty 2001;16:134-9.

17. Calder PR, Hynes MC, Scott G. Short-term results of hemi-resurfacing for osteonecrosis of the femoral head. Hip Int 2004;14:174-81.

18. Calder JD, Pearse MC, Revell PA. The extent of osteocyte death in the proximal femur of patients with osteonecrosis of the femoral head. J Bone Joint Surg $[\mathrm{Br}]$ 2001;83-B:419-22.

19. Steffen RT, Smith SR, Urban JP, et al. The effect of hip resurfacing on oxygen concentration in the femoral head. J Bone Joint Surg [Br]2005;87-B:1468-74.

20. Little CP, Ruiz AL, Harding IJ, et al. Osteonecrosis in retrieved femoral heads after failed resurfacing arthroplasty of the hip. J Bone Joint Surg [Br] 2005;87-B:320-3.

21. Seiler JG 3rd, Christie MJ, Homra L. Correlation of the findings of magnetic resonance imaging with those of biopsy in patients who have stage I or II ischaemic necrosis of the femoral head. J Bone Joint Surg [Am] 1989;71-A:28-32.

22. Jergesen HE, Lang $\mathbf{P}$, Moseley M, Genant HK. Histologic correlation in magnetic resonance imaging of femoral head osteonecrosis. Clin Orthop 1990;253:150-63.

23. Ficat RP, Arlet J. Ischémie et necrose osseuses. Paris: Masson, 1977:224.
24. Hauzer JP, Sintzoff S Jr, Appelboom T, et al. Relationship between magnetic resonance imaging and histologic findings by bone biopsy in nontraumatic osteonecrosis of the femoral head. J Rheumatol 1992;19:385-92.

25. No authors listed. ARCO committee on terminology and classification. ARCO News 1992;4:41-6.

26. Arlet J, Durroux R. Diagnostic histologique précoce de l'ostéonecrose ascéptique de la tete femorale par le forage biopsie. In: Premier symposium international de circulation osseuses. Toulouse: INSERM, 1973

27. Humphreys S, Spencer JD, Tighe JR, Cumming RR. The femoral head in osteonecrosis: a quantitative study of osteocyte population. J Bone Joint Surg [Br] 1989;71-B:205-8.

28. Parvizi J, Campfield A, Clohisy JC, Rothman RH, Mont MA. Management of arthritis of the hip in the young adult. J Bone Joint Surg [Br]2006;88-B:1279-85.

29. Amstutz HC, Campbell PA, Le Duff MJ. Fracture of the neck of the femur after surface arthroplasty of the hip. J Bone Joint Surg [Am] 2004;86-A:1874-7.

30. Pollard TC, Baker RP, Eastaugh-Waring SJ, Bannister GC. Treatment of the young active patient with osteoarthritis of the hip: a five- to seven-year comparison of hybrid total hip arthroplasty and metal-on-metal resurfacing. J Bone Joint Surg [Br] 2006;88-B:592-600.

31. Bishop AR, Roberson JR, Eckman JR, Fleming LL. Total hip arthroplasty in patients who have sickle-cell haemoglobinopathy. J Bone Joint Surg [Am] 1988:70A:853-5.

32. Acurio MT, Friedman RJ. Hip arthroplasty in patients with sickle-cell haemoglobinopathy. J Bone Joint Surg [Br] 1992;74-B:367-71.

33. Clarke HJ, Jinnah RH, Brooker AF, Michaelson JD. Total replacement of the hip for avascular necrosis in sickle cell disease. J Bone Joint Surg [Br] 1989;71-B:464-70. 